\title{
CLINICAL AND RADIOLOGICAL EVALUATION OF PATIENTS WITH SUBARACHNOID HAEMORRHAGE SUBJECTED TO DIGITAL SUBTRACTION ANGIOGRAPHY IN AL-HUSSEIN NEURO-INTERVENTION UNIT
}

By

\author{
Khaled Muhammad Sobh ${ }^{1}$, Muhammad Salah Al Fishawy ${ }^{2}$, Mahmoud \\ Galal $^{1}$, and Muhammad Fadel Muhammad ${ }^{1}$ \\ ${ }^{1}$ Neurology and ${ }^{2}$ Radiology Departments, Faculty of Medicine, Al-Azhar University \\ Corresponding author: Muhammad Fadel Muhammad,
}

E-mail: $\underline{\text { m_fadel1991@yahoo.com }}$

\begin{abstract}
Background: Subarachnoid hemorrhage (SAH) refers to bleeding that occurs primarily within the subarachnoid space, in between cases of spontaneous SAH and rupture of an intracranial saccular aneurysm accounts for approximately $85 \%$.

Objectives: The aim of this study was to assess clinical presentation, risk factors and the etiology of subarachnoid hemorrhage in a sample of Egyptian patients, and also assess the outcome of endovascular management and complications.

Patients and Methods: The study was carried out on patients with SAH who were subjected to endovascular neuro-intervention unit in AL-Hussein University Hospital, including patients with SAH retrospectively from 2006 to 2018, and the newly diagnosed patients during 2019.

Results: During the period from May 2006 to May 2019, 560 patients with SAH has been admitted. 136 patients $(24.2 \%)$ were excluded from the study as they were critically ill. Their Hunt and Hess score were 4 to 5 . Also, another 51 has been excluded due to missed files or discharge against medical advice. The remaining 373 patients. 145 patients were angiographically free, Patients with aneurysm were 228 patients, 77 patients died before therapeutic endovascular treatment as they delayed due to financial troubles, The remaining patients were 151, The most common type of aneurysm between those patients was anterior communicating aneurysm $(27.8 \%)$, then MCA aneurysm (17.8\%), posterior communicating artery aneurysm $(13.9 \%)$, para-ophthalmic artery aneurysm (6.6 \%), basilar artery aneurysm (5.9\%), posterior inferior cerebellar artery aneurysm (6.4\%), supraclinoid carotid artery aneurysm (3.1\%), peri callossal artery aneurysm $(3.3 \%), \mathrm{T}$ carotid artery aneurysm $(7.2 \%)$, superior cerebellar artery aneurysm (1.9\%), inferior cerebellar artery aneurysm (2.6\%) and multiple aneurysms $(6.6 \%)$. The complications of endovascular treatment in studied patients occurred in 13 patients $(3.4 \%)$ in the form of aneurysmal rupture, coil displacement, hydrocephalus and vessel rupture.

Conclusion: Cerebral catheter angiography is a safe, feasible and efficacious procedure. The new technique in the endovascular management of the cerebral aneurysm as balloon or stent assisted technique and flow diverter stent is greatly reducing the complication rate and making the outcome is very promising.
\end{abstract}

Keywords: Subarachnoid Hemorrhage, Digital Subtraction Angiography. 


\section{INTRODUCTION}

Classical clinical presentation of SAH is characterized by a sudden and explosive headache never felt in the patient's clinical history. Disturbed consciousness occurs in almost half of the patients and focal neurological signs develop afterward in one-third of the cases (Mac Grory et al., 2018).

Primary causes of death were direct effect of the primary hemorrhage, aneurysm rebleeding, cerebral infarction from vasospasm, refractory cerebral edema leading to brain stem herniation, hydrocephalus, operative complications and medical complications, e.g., fatal arrhythmia, pulmonary embolism, or multisystem organ failure (Jeon et al., 2013).

The progress experienced in the management and treatment of patients suffering from SAH allowed a marked improvement in prognosis, achieving a reduction in the mortality rate and not increasing the number of patients remaining in a persistent vegetative state or developing severe disability (Ayling et al., 2016).

The primary goal of treatment was to exclude the aneurysm sac from the intracranial circulation while preserving the parent artery (Wiebers et al., 2017).

The aim of this study was to assess clinical presentation, risk factors and the etiology of subarachnoid hemorrhage in a sample of Egyptian patients, and also assess outcome after endovascular management and complications.

\section{PATIENTS AND METHODS}

The study was carried out on patients with SAH admitted in stroke units of AlHussein University Hospital and Bab AlShaeria University Hospital, retrospectively from 2006 to 2018 and the newly diagnosed patients during 2019 who were subjected to endovascular management at Al-Hussein Neurointervention.

A written consent had been taken from every patient or his caregiver before starting of endovascular treatment.

\section{Inclusion criteria:}

Patients were selected after confirmation of SAH clinically (patient presented with $\mathrm{SAH}$ ) and radiologically by doing CT scan of the brain and laboratory as lumbar puncture in case of -ve CT scan. The included patients were at age between 18 -80 years old patients and their Hunt and Hess grade up to 3.

\section{Exclusion criteria:}

Patients with traumatic SAH, hemorrhagic blood disease, poor clinical Hunt - Hess grade (grade 4, 5), and contraindications to 4 vessels angiography as renal failure and allergy.

All the patients were subjected to full neurological history and examination. Categorization of patients was according to the severity using Hunt-Hiss grading scale. Radiological investigation: Non contrast CT brain to detect the site of SAH through Fisher grading scale, CT angiography for diagnosis of aneurysm. Digital subtraction angiography for confirmation of the presence of aneurysm or vascular malformation and determine the mode of treatment. Laboratory 


\section{CLINICAL AND RADIOLOGICAL EVALUATION OF PATIENTS WITH...}

investigation: $\mathrm{CBC}, \mathrm{PT}, \mathrm{INR}$, renal function test and liver function test, hepatitis markers, CSF analysis for xanthochromia in case of negative CT brain. Modality of treatment was according to the etiology as coiling either simple or balloon remodeling and/or stent assisted coil technique or flow diverter stent in case of Aneurysm and embolization in case of other vascular malformations.

The patient was assessed post procedural for any neurological deficit and after 24 hours as well as assessment of complications and death rate in $\mathrm{SAH}$.

\section{RESULTS}

This study was designed to make a scope on patients with SAH who were subjected to endovascular treatment in our stroke unit. During the period from May 2006 to May 2019, we had 560 patients with $\mathrm{SAH}$; their mean age of them was $42.7 \pm 9.4$ years.

We had 136 patients (24.2\%) excluded from the study as they were critically ill and their Hunt and Hess score were 4 to 5, another $51(9.1 \%)$. Missed patients have been excluded due to incomplete data of them and part of them was discharged against medical advice.

The remaining patients (373 patients) were subjected to endovascular diagnostic unit; 145 patients $(38.8 \%)$ of them were angiographically free, and 228 patients $(60.2 \%)$ had aneurysm; 77 patients of them $(33.7 \%)$ died during the period between admission and doing the endovascular management. Their causes of death were 31 patients (40.2\%) had rebleeding, 23 patients $(29.2 \%)$ had early vasospasm, 11 patients (14.2\%) had pulmonary embolism, and 12 patients $(15.5 \%)$ had cardiac arrhythmia.

The mean age in this study in included patient was $38 \pm 9.4$, and $53 \%$ of them were males (Table 1). However, in patients with aneurysmal SAH, females were more common than males (Table 2).

As regard comorbidities and risk factors in the studied patients. The most common risk factor is hypertensive $(44.1 \%)$ patients then diabetic patients. 
Table (1): Description of age and sex in studied patients

\begin{tabular}{|c|c|c|c|}
\hline \multicolumn{2}{|l|}{ Variables } & \multirow{2}{*}{\multicolumn{2}{|c|}{$\frac{\text { Studied patients }(\mathrm{N}=373)}{38 \pm 9.4}$}} \\
\hline \multirow{2}{*}{ Age (years) } & Mean \pm SD & & \\
\hline & Min - Max & \multicolumn{2}{|c|}{$22-74$} \\
\hline \multirow{2}{*}{ Sex } & Male & 198 & $53.1 \%$ \\
\hline & Female & 175 & $46.9 \%$ \\
\hline \multirow{2}{*}{ HTN } & Non & 208 & $55.8 \%$ \\
\hline & Known & 165 & $44.2 \%$ \\
\hline \multirow{2}{*}{ DM } & Non & 290 & $\mathbf{7 7 . 8 \%}$ \\
\hline & Known & 83 & $22.2 \%$ \\
\hline \multirow{2}{*}{ Smoking } & Non & 315 & $84.5 \%$ \\
\hline & Smoker & 58 & $15.3 \%$ \\
\hline \multirow{2}{*}{$\begin{array}{l}\text { History of infective endocarditic } \\
\text { and rheumatic heart disease }\end{array}$} & No & 365 & $97.8 \%$ \\
\hline & Yes & 8 & $2.2 \%$ \\
\hline \multirow{2}{*}{ Family history of aneurysm } & No & 355 & $95.2 \%$ \\
\hline & Yes & 18 & $4.8 \%$ \\
\hline
\end{tabular}

Comparison between patients who were angiographically free versus the patients with aneurysm. The percentage of males were $(51.6 \%)$, females were $(48.4 \%)$ The reverse occurred in the other group in which the female patients were $53 \%$, and males were $47 \%$. The noncontract enhanced brain CT revealed in the angiographically free group that the perimesencphalic cases were $70 \%$ and the non-peri mesencephalic cases were $30 \%$, while in the other group the perimesencphalic cases were $10.1 \%$ and the non-peri mesencephalic cases were $89.9 \%$, the clinical assessment through the HUNT-HESS grading scale it revealed that the severity is the more in the patient with aneurysm (Table 2)

Table (2): Comparison between patients who are angiographically free versus with aneurysm $(\mathrm{N}=373)$

\begin{tabular}{|c|c|c|c|c|}
\hline Groups & \multicolumn{2}{|c|}{$\begin{array}{l}\text { Patients who were } \\
\text { angiographically free } 145 \\
(38.8 \%)\end{array}$} & \multicolumn{2}{|c|}{$\begin{array}{l}\text { Patients with aneurysm } 228 \\
(61.2 \%)\end{array}$} \\
\hline $\begin{array}{l}\text { Male to } \\
\text { female ratio }\end{array}$ & \multicolumn{2}{|l|}{$62.1 \%: 37.9 \%$} & \multicolumn{2}{|l|}{$47.4 \%: 52.6 \%$} \\
\hline $\begin{array}{l}\text { CT } \\
\text { hemorrhage }\end{array}$ & $\begin{array}{l}\text { Perimesencep } \\
\text { halic } \\
\mathbf{7 0 \%} \\
101 \text { patients }\end{array}$ & $\begin{array}{l}\text { Non peri } \\
\text { mesencephalic } \\
30 \% \\
44 \text { patients }\end{array}$ & $\begin{array}{l}\text { Perimesencep } \\
\text { halic } \\
10.1 \% \\
23 \text { patients }\end{array}$ & $\begin{array}{l}\text { Non peri } \\
\text { mesencephalic } \\
89.9 \% \\
205 \text { patients }\end{array}$ \\
\hline $\begin{array}{l}\text { Hunt-Hess } \\
\text { grading scale }\end{array}$ & \multicolumn{2}{|l|}{$1-2$} & \multicolumn{2}{|l|}{$2-3$} \\
\hline
\end{tabular}




\section{CLINICAL AND RADIOLOGICAL EVALUATION OF PATIENTS WITH...}

The most common neurological symptoms in the included patients was headache $48.6 \%, 0.4 \%$ patients presented by headache with ataxia, (10\%) patients presented by headache and Disturbed conscious level (DCL), 6.6\% patients presented by headache and 3rd nerve palsy, $4.3 \%$ patients presented by headache and neck stiffness, $9.6 \%$ patients presented by fits, $3.6 \%$ patients presented by DCL and fits, $4.6 \%$ patients presented by DCL and left side weakness, $6.4 \%$ patients presented by DCL and meningeal irritation signs, and $5.9 \%$ patients presented by DCL and right side weakness (Table 3).

Table (3): Description of clinical presentation in studied patients

\begin{tabular}{|l|c|c|}
\hline Clinical presentation & $\begin{array}{c}\text { Patients } \\
(\mathbf{n}=373)\end{array}$ & Percent \% \\
\hline Headache & 181 & $48.5 \%$ \\
\hline Headache and ataxia & 2 & $\mathbf{0 . 5 \%}$ \\
\hline Headache and DCL & 37 & $9.9 \%$ \\
\hline Headache and 3rd nerve palsy & 24 & $\mathbf{6 . 4 \%}$ \\
\hline Headache neck stiffness & 17 & $4.6 \%$ \\
\hline Fits & 35 & $9.4 \%$ \\
\hline DCL and fits & 13 & $3.5 \%$ \\
\hline DCL and left side weakness & 18 & $4.8 \%$ \\
\hline DCL and Meningeal irritation signs & 24 & $6.4 \%$ \\
\hline DCL and Right-side weakness & 22 & $5.9 \%$ \\
\hline
\end{tabular}

Anterior communicating artery aneurysm occurred in $26.7 \%$ of patients, MCA aneurysm in $18.4 \%$, posterior communicating aneurysm in $13.2 \%$, paraophthalmic artery aneurysm in $7 \%$, basilar artery aneurysm in $7.9 \%$, posterior inferior cerebellar artery aneurysm in $4.3 \%$, supraclenoid carotid artery aneurysm in $3 \%$, peri callossal artery aneurysm in $3.5 \%, \mathrm{~T}$ carotid artery aneurysm patients in $7.9 \%$, superior cerebellar artery aneurysm in $1.8 \%$, inferior cerebellar artery aneurysms in $1.7 \%$, and multiple aneurysms in $4.3 \%$ of patients (Table 4). 
KHALED MUHAMMAD SOBH et al.,

Table (4): Type of aneurysms according to site Total number $=228$

\begin{tabular}{|l|c|c|c|c|}
\hline Parameters & $\begin{array}{c}\text { Died } \\
\text { cases } \\
\text { Site of aneurysm }\end{array}$ & $\begin{array}{c}\text { percent } \\
(32.8 \%)\end{array}$ & $\begin{array}{c}\text { Therapeutic } \\
\text { Endovascular } \\
\text { management } \\
(\mathbf{N = 1 5 1})\end{array}$ & $\begin{array}{c}\text { Percent } \\
66.2 \%\end{array}$ \\
\hline $\begin{array}{l}\text { Anterior communicating } \\
\text { aneurysm }\end{array}$ & 19 & $24.7 \%$ & 42 & $27.8 \%$ \\
\hline $\begin{array}{l}\text { Middle cerebral artery } \\
\text { aneurysm }\end{array}$ & 15 & $17.5 \%$ & 27 & $17.9 \%$ \\
\hline $\begin{array}{l}\text { Posterior communicating } \\
\text { artery aneurysm }\end{array}$ & 9 & $11.7 \%$ & 21 & $13.9 \%$ \\
\hline $\begin{array}{l}\text { Para-ophthalmic artery } \\
\text { aneurysm }\end{array}$ & 6 & $7.8 \%$ & 10 & $6.6 \%$ \\
\hline Basilar artery aneurysm & 9 & $11.7 \%$ & 9 & $6 \%$ \\
\hline $\begin{array}{l}\text { Posterior inferior } \\
\text { cerebellar artery }\end{array}$ & 5 & $6.5 \%$ & 5 & $3.3 \%$ \\
\hline $\begin{array}{l}\text { Supraclenoid carotid } \\
\text { artery aneurysm }\end{array}$ & 3 & $3.9 \%$ & 4 & $2.6 \%$ \\
\hline $\begin{array}{l}\text { Peri callossal artery } \\
\text { aneurysm }\end{array}$ & 3 & $3.9 \%$ & 5 & $3.3 \%$ \\
\hline $\begin{array}{l}\text { T-carotid artery } \\
\text { aneurysm }\end{array}$ & 7 & $9.1 \%$ & 11 & $7.3 \%$ \\
\hline $\begin{array}{l}\text { Superior cerebellar artery } \\
\text { aneurysm }\end{array}$ & 1 & $1.3 \%$ & 3 & $2 \%$ \\
\hline $\begin{array}{l}\text { inferior cerebellar artery } \\
\text { aneurysm }\end{array}$ & & & 4 & $2.6 \%$ \\
\hline Multiple aneurysms & & & 10 & $6.6 \%$ \\
\hline
\end{tabular}

The most common type of aneurysm was saccular aneurysm (76.3) followed by fusiform aneurysm (10\%), and $13.5 \%$ had dissecting aneurysm. $95.1 \%$ of patients had spontaneous aneurysm formation, while $4.9 \%$ of patients had aneurysm due to infection (mycotic). The aneurysm in
$67.2 \%$ patients measured less than $10 \mathrm{ml}$, while $21 \%$ measured from 10 to $25 \mathrm{ml}$, and in $11.8 \%$ measured $25 \mathrm{ml}$. There were $64.9 \%$ patients had narrow neck aneurysm, while $35.1 \%$ patients had wide neck aneurysms (Table 5). 


\section{CLINICAL AND RADIOLOGICAL EVALUATION OF PATIENTS WITH...}

Table (5): Description of type of aneurysm according to the Shape, Etiology, Size and Neck size.

\begin{tabular}{|c|c|c|c|}
\hline & Variables & $\begin{array}{l}\text { Studied } \\
\text { patients }\end{array}$ & Percent \\
\hline Shape of & $\begin{array}{l}\text { Saccular aneurysm } \\
\text { (Berry aneurysm) }\end{array}$ & 174 & $76.3 \%$ \\
\hline aneurysm & Fusiform aneurysm & 23 & $10.1 \%$ \\
\hline & Dissecting aneurysm & 31 & $13.5 \%$ \\
\hline Etiology of & Spontaneous & 220 & $96.5 \%$ \\
\hline aneurysm & Mycotic & 8 & $3.5 \%$ \\
\hline & Less than $10 \mathrm{ml}$ & 153 & $67.1 \%$ \\
\hline $\begin{array}{l}\text { Size of } \\
\text { aneurvsm }\end{array}$ & From 10 to $25 \mathrm{ml}$ & 48 & $21.1 \%$ \\
\hline & More than $25 \mathrm{ml}$ & 27 & $11.8 \%$ \\
\hline Neck of & Narrow & 148 & $64.9 \%$ \\
\hline aneurysm & Wide & 80 & $35.1 \%$ \\
\hline
\end{tabular}

Complication occurred in 13 patients (3.4\%). Aneurysmal rupture occurred in 2 patients $(0.5 \%)$ and they were treated with insertion of another micro-catheter and use of balloon to allow hemostasis and complete impaction of aneurysm with coils, Clinically, the patients had no neurological deficit, Coil displacement occurred in 4 patients $(1.1 \%)$ with usage of stent to allow coadaptation of coils towards the wall, Hydrocephalus occurred in 1 patient $(0.2 \%)$ and treated with V.P shunt, Vessel rupture occurred in 1 patient $(0.2 \%)$. Vasospasm occurred in 6 patients $(1.6 \%)$ who were treated by balloon dilation and medical treatment by rising the blood pressure where 4 of them had transient hemiparesis and the other 2 patients had permanent weakness (Table 6).

Table (6): Complication of endovascular techniques.

\begin{tabular}{|l|l|l|l|}
\hline Complications & $\begin{array}{l}\text { Patient } \\
(\mathrm{n}=13)\end{array}$ & $\begin{array}{l}\text { Percent } \\
\mathbf{3 . 5 \%}\end{array}$ & Treatment \\
\hline Aneurysmal rupture & 2 & $\mathbf{0 . 5 \%}$ & $\begin{array}{l}\text { Insertion of another micro catheter } \\
\text { and use of balloon }\end{array}$ \\
\hline Coil displacement & 4 & $1.1 \%$ & Stent assisted technique \\
\hline Hydrocephalus & 1 & $\mathbf{0 . 2 \%}$ & V.P shunt \\
\hline Vessel rupture & 1 & $\mathbf{0 . 2} \%$ & Parent artery occlusion \\
\hline vasospasm & 6 & $\mathbf{1 . 6 \%}$ & $\begin{array}{l}\text { Balloon dilation } \\
\text { and medical treatment as rising } \\
\text { blood pressure }\end{array}$ \\
\hline
\end{tabular}




\section{DISCUSSION}

Subarachnoid hemorrhage is a life threating type of stroke that have a high mortality and morbidity and needs emergent interference to prevent the complication, this study is designed to ass the clinical presentation and the intervention manner of patient with $\mathrm{SAH}$ : As regard the gender of the candidates there were $(53 \%)$ males and $(47 \%)$ females. This agreed with study done by chen et al. (2011) that found $56.7 \%$ males and 43.3 females among the studied patients.

It disagrees with the study done by Gunia et al. (2016) in which the results of 80 patients $37(46.25 \%)$ men and 43 $(53.75 \%)$ women.

This can be explained that the male patients in Egypt had a higher ratio of smoking than the females making them more prone to have $\mathrm{SAH}$ as the percentage of smoking in male patient is $50.1 \%$ However the cases with aneurysmal rupture females are more common than male this me reflect the decrease in level of hormones may play a role in aneurysm rupture as most of females in this sub-group is menopause.

Regarding age, the mean age of the patients were $38 \pm 9.4$; while in study by Kranthi et al. (2016), the age range of the candidates was 41-72 with mean of 51.3.

A $44.1 \%$ of the patients were known to be hypertensive, while $55.9 \%$ were non hypertensive this percentage is more than the study done by Fattahian et al. (2018) where $84(32.9 \%)$ were found to be hypertensive and less than the study done Kranthi et al. (2016) where $63.1 \%$ of cases where known to be hypertensive.
We also found that only $22.1 \%$ were diabetic and $44.2 \%$ were smoker and this percentage is less than Fattahian et al. (2018), which found $17 \%$ diabetic among the candidates and $30 \%$ were smoker.

As regard clinical presentation, there were $(48.6 \%)$ patients presented by headache, (21.4\%) headache and associated symptom, (9.6\%) patients presented by fits, the percentage of patient who developed D.C.L is $(20.6 \%)$ and $23.5 \%$ developed weakness and seizure as $(3.6 \%)$ patients presented by DCL and fits, $(4.6 \%)$ patients presented by D.C.L and left side weakness, $(6.4 \%)$ patients presented by D.C.L and Meningeal irritation signs and (5.9\%) patients presented by D.C.L and Right side weakness.

This agreed with the study ran by Kumar et al. (2010) they found that $75 \%$ the patients with a SAH complained of headache.

In this study $20.6 \%$ developed D.C.L and this percentage is less than the percentage of patient with DCL in the study done by Kumar et al. (2010) the most frequent presenting symptom in patients was a severe headache $(75 \%)$ of abrupt onset $(56 \%)$. Patients usually had temporary sensory or motor symptoms (54\%). In a small group of patients, the presentation was more varied and included lethargy, fever, and confusion.

As regard anterior communicating aneurysm patients were $26.7 \%$, MCA aneurysm were $18.4 \%$, posterior communicating aneurysm were $13.2 \%$, para-ophthalmic artery aneurysm patients were $7 \%$, basilar artery aneurysm were $7.9 \%$, posterior inferior cerebellar artery aneurysm were $4.3 \%$, supraclenoid carotid 


\section{CLINICAL AND RADIOLOGICAL EVALUATION OF PATIENTS WITH...}

artery aneurysm were $3 \%$, peri callossal artery aneurysm were $3.5 \%, \mathrm{~T}$ carotid artery aneurysm patients were $7.9 \%$, superior cerebellar artery aneurysm were $1.8 \%$, inferior cerebellar artery aneurysms were $1.7 \%$, and Multiple aneurysms were $4.3 \%$.

In the study by Kang et al. (2018), an analysis of 185 cases of aneurysmal SAH showed that the location of aneurysms was internal carotid artery in $(32.5 \%)$, anterior communicating artery in $(35.1 \%)$, middle cerebral artery in (20\%), and posterior circulation in $(12.4 \%)$. In the study ran by Fattahian et al. (2018) aneurismal SAH patients, the location of aneurysms in $34.7 \%$ was anterior communicating artery, $33.4 \%$ in middle cerebral artery, $13.9 \%$ internal carotid artery, $9.7 \%$ in posterior fossa, and $8.3 \%$ in anterior cerebral artery.

Badry et al. (2014) found that the middle cerebral artery aneurysms (number $=10$ aneurysms) were it the most common site followed by the anterior communicating artery aneurysms (number $=8$ aneurysms), posterior cerebral arteries aneurysms (number $=8$ aneurysms), the internal carotid arteries and posterior communicating aneurysms (number $=4$ aneurysms) for each and the ophthalmic artery aneurysms, anterior choroidal artery aneurysms and vertebrobasilar junction aneurysms (number $=2$ aneurysms) for each of them and finally basilar artery aneurysm (number $=1$ aneurysm)

As regard the size of aneurysm, there were $67.2 \%$ of patients have aneurysm measure less than $10 \mathrm{ml}$, while $21 \%$ of patients have aneurysm measure from 10 to $25 \mathrm{ml}$, and in $11.8 \%$ of patients have aneurysm measure $25 \mathrm{ml}$. This agreed with the study done by Ahmed et al. (2015).

As regard the shape of aneurysm, there were $76.3 \%$ patients have saccular aneurysm, while $13.5 \%$ patients have dissecting aneurysm, and (10 \%) patients had fusiform aneurysm.

In the study done by Ahmed. et al. (2015), there were 29 (82.9\%) patients of saccular shape, $2(5.7 \%)$ patients of fusiform, shape and $4(11.4 \%)$ patients of bilobed shape.

As regard the size of the neck there were $(64.9 \%)$ patients had narrow neck aneurysm while $(35.1 \%)$ patients had wide neck aneurysms this disagreed with the study done by Ahmed et al. (2015) as there were 17 (48.6\%) patients of narrow neck $(<2 \mathrm{~mm})$ and $18(51.4 \%)$ patients of wide neck ( $>2 \mathrm{~mm})$.

As regard comparison between patients who are angiographically free versus with aneurysm; the ratio of male $(62 \%)$ patients and females (38\%) patients in angiographically free patients and the reverse occurred in the other group which female patients were $(52.6 \%)$ and males were $(47.4 \%)$ with aneurysm and the noncontract enhanced the pattern of CT hemorrhage: it revealed in the angiographically free group that the premesencphalic cases were $70 \%$ and the non premesencephalic cases were $30 \%$ while in the group with aneurysm the premesencphalic cases were $10.1 \%$ and the non premesencephalic cases were 89.9 $\%$.

This disagreed with study done by Coelho et al. (2016) on 62 patient who had SAH with free endovascular 
angiography results in which $(46.8 \%$ peri mesencephalic subarachnoid hemorrhage; $53.2 \%$ - non-peri mesencephalic subarachnoid hemorrhage) the ratio of male $(44.8 \%)$ patients and females $(54.5 \%)$.

The complications in studied patients who underwent the endovascular management were $3.4 \%$ in the form of aneurysmal rupture occurred in $0.5 \%$ of patients. Coil displacement occurred in $1.1 \%$ of patients, Hydrocephalus occurred in $0.2 \%$ of patients, Vessel rupture occurred in $0.2 \%$ of patients, and vasospasm occurred in $1.6 \%$ of patients. While in the study done in 2010 by Thiex that found the percentage of complications is $3.4 \%$ of patients with $2.1 \%$ groin hematoma and $1.3 \%$ cases with vasospasm Hanak et al. (2012). And also, in the study done by Ahmed et al. (2013) in which they found complications were in the form of hemiparesis $10 \%$ (three cases; two of them were transient while one of them was permanent), hemiparesis is suggested to be due to vasospasm as a complication of SAH, Hydrocephalus occurred in three cases $(10 \%)$ as a sequela of SAH for which a ventriculo-peritoneal (VP) shunt was applied.

\section{CONCLUSION}

- Cerebral catheter angiography is a safe, feasible and efficacious procedure.

- The new technique in the endovascular management of the cerebral aneurysm as balloon using, stent assisted technique and flow divertor stent is greatly reducing the complication rate and making the out come is very good comparable with previous years.
- The good choice of the line of treatment is markedly reducing the complication rate.

- Whenever the experience in endovascular managemn is increasing it will lead to good management of complication.

- Early intervention in the first few days of SAH before the period of vasospasm improving the outcome.

\section{REFERENCES}

1. Ahmed, A. Z., Zohdi, A. M., Zaghloul, M. $S$ and ElSamman, A. K. (2013): Endovascular coiling versus surgical clipping in the treatment of ruptured anterior communicating artery aneurysm in Cairo University Hospitals. The Egyptian Journal of Radiology and Nuclear Medicine, 44(3): 523-530.

2. Ahmed, M., Nasir, H., Khan, $A$ and Anwar, K. (2015): To Compare Aneurysmal Findings of CTA with Surgical Findings in Patients of Aneurysmal Subarachnoid Haemorrhage. Pakistan Journal of Neurological Surgery, 19(4): 241-245.

3. Ayling, O. G., Ibrahim, G. M., Alotaibi, N. M., Gooderham, P. A and Macdonald, R. L. (2016): Dissociation of early and delayed cerebral infarction after aneurysmal subarachnoid hemorrhage. Stroke, 47(12): 2945-2951.

4. Badry, A., Elshafey, $R$ and Khalil, M. (2014): Detection, characterization and endovascular therapy planning of intracranial aneurysms with 16-channel multidetector row CT angiography. The Egyptian Journal of Radiology and Nuclear Medicine, 45(1): 151158.

5. Chen, G., Fang, Q., Zhang, J., Zhou, D and Wang, Z. (2011): Role of the Nrf2-ARE pathway in early brain injury after experimental subarachnoid hemorrhage. Journal of Neuroscience Research, 89(4): 515-523. 
6. Coelho, L. G. B. S. A., Costa, J. M. D and Silva, E. I. P. A. (2016): Non-aneurysmal spontaneous subarachnoid hemorrhage: peri mesencephalic versus non-peri mesencephalic. Revista Brasileira de Terapia Intensiva, 28(2): 141.

7. Fattahian, R., Shahsavari, $\mathbf{N}$ and Sadeghi, M. (2018): Epidemiological Factors of Nontraumatic Subarachnoid Hemorrhage and Complications during Hospitalization in Kermanshah's Educational Hospitals. Journal of Research in Medical and Dental Science, 6(2): 327-331.

8. Gunia, D. D., Ekvtimishvili, E. T and Basiladze, G. Z. (2016): Using of modern endovascular methods and techniques in treatment of complex aneurysms. Journal of Endovascular Neuroradiology, 2: 22-28.

9. Hanak, B. W., Zada, G., Nayar, V. V., Thiex, R., Du, R., Day, A. L and Laws, E. R. (2012): Cerebral aneurysms with intrasellar extension: a systematic review of clinical, anatomical, and treatment characteristics: A review. Journal of neurosurgery, 116(1): 164-178.

10. Jeon, S. B., Parikh, G., Choi, H. A., Badjatia, N., Lee, K., Schmidt, J. $M$ and Claassen, J. (2013): Cerebral microbleeds in patients with acute subarachnoid hemorrhage. Neurosurgery, 74(2): 176-181.

11. Kang, J., Kang, C. H., Roh, J., Yeom, J. A., Shim, D. H., Kim, Y. S and Kim, S. K. (2018): Feasibility, Safety, and Follow-up Angiographic Results of Endovascular
Treatment for Non-Selected Ruptured Intracranial Aneurysms Under Local Anesthesia with Conscious Sedation. Journal of Neurocritical Care, 11(2): 93-101.

12. Kranthi, S., Sahu, B. $P$ and Aniruddh, $P$. (2016): Factors affecting outcome in poor grade subarachnoid haemorrhage: An institutional study. Asian Journal of Neurosurgery, 11(4): 365.

13. Kumar, S., Goddeau, R. P., Selim, M. H., Thomas, A., Schlaug, G., Alhazzani, A and Caplan, L. R. (2010): Atraumatic convexal subarachnoid hemorrhage: clinical presentation, imaging patterns, and etiologies. Neurology, 74(11): 893-899.

14. Mac Grory, B., Vu, L., Cutting, S., Marcolini, E., Gottschalk, C and Greer, D. (2018): Distinguishing characteristics of headache in nontraumatic subarachnoid hemorrhage. Headache: The Journal of Head and Face Pain, 58(3): 364-370.

15. Song, J. P., Ni, W., Gu, Y. X., Zhu, W., Chen, L., Xu, B and Mao, Y. (2017): Epidemiological Features of Nontraumatic Spontaneous Subarachnoid Hemorrhage in China: A Nationwide Hospital-based Multicenter Study. Chinese Medical Journal, 130(7): 776.

16. Wiebers, D. O. (2006): Unruptured intracranial aneurysms: natural history and clinical management. Update on the international study of unruptured intracranial aneurysms. Neuroimaging Clinics, 16(3): 383-390. 
التقييم الإكلينيكي وبالأشعة للمرضي الذين بعانون من نزيف

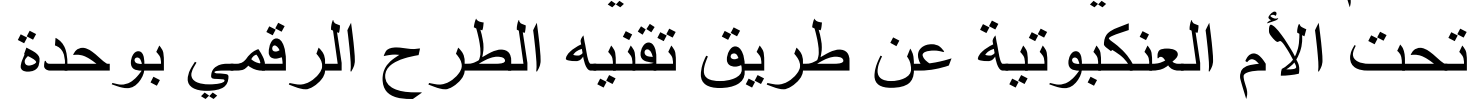

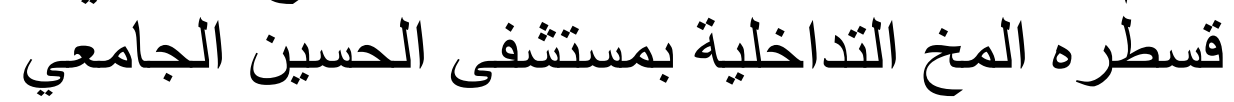

خالد محمد صبح، محمد صالح الفيشاوي*، محمود جلال، محمد فاضل محمد قسمي طب المخ والاعصاب و الأشعة التثخيصية*، كلية الطب، جامعة الأزهر

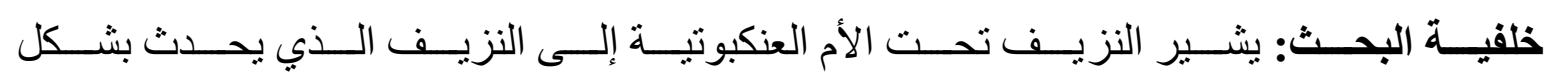

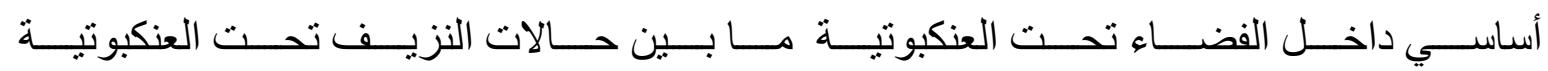

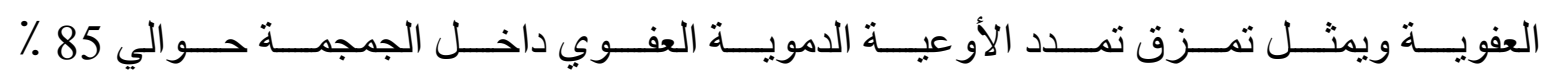
من الحالات.

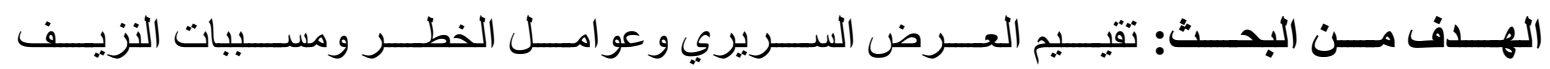

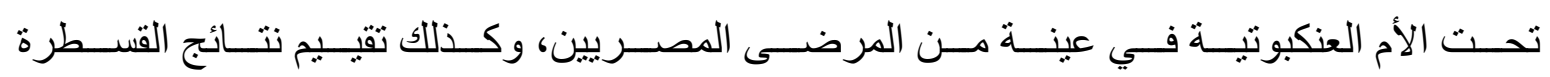
التداخلية و المضاعفات نتيجة التنخل بالقسطرة.

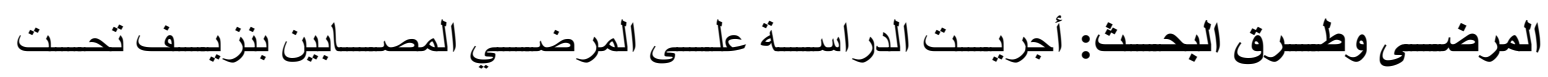

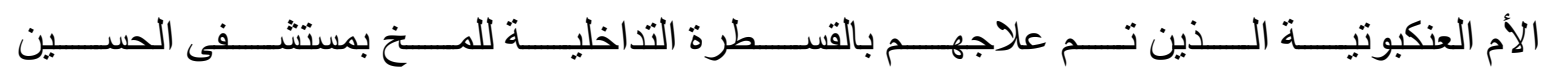

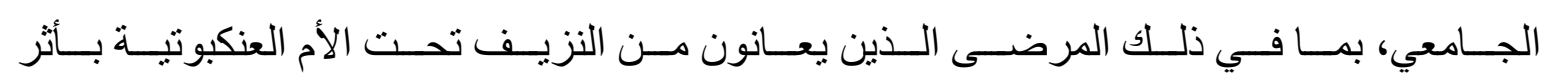

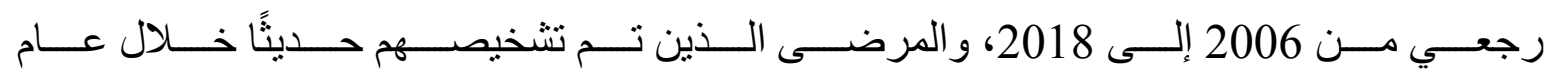

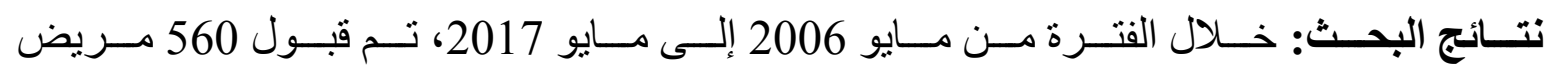

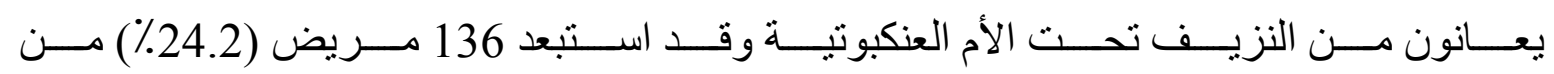

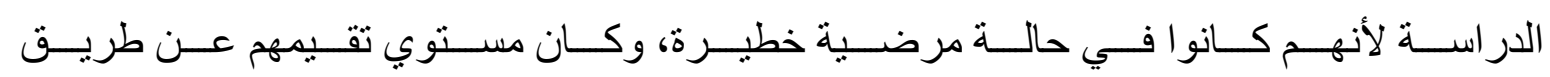

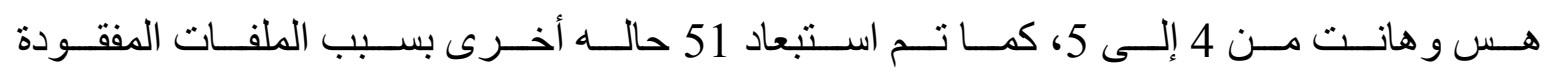

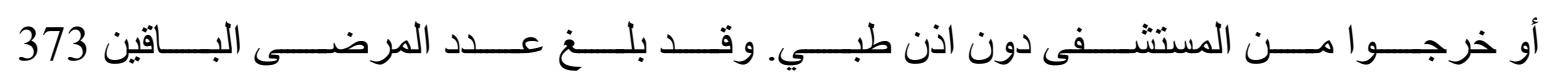

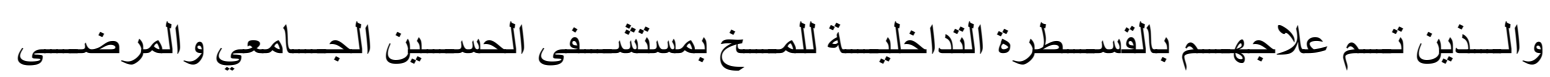










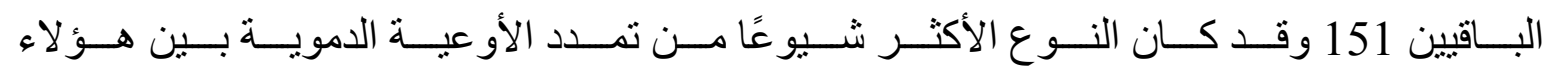

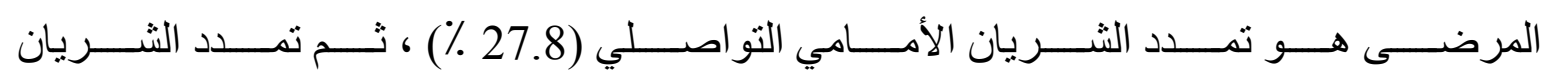

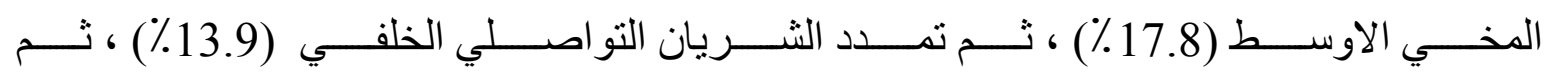



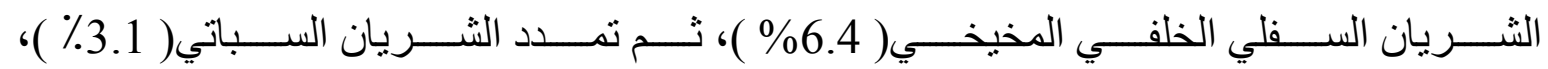

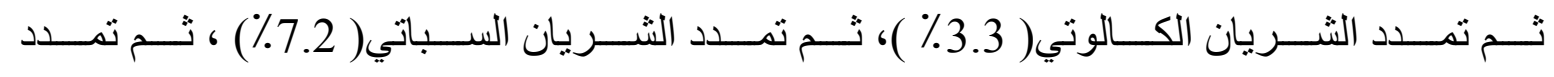

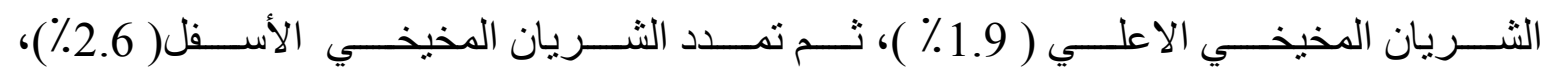

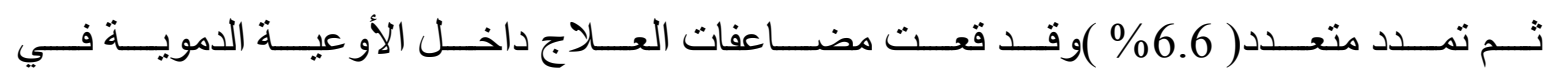

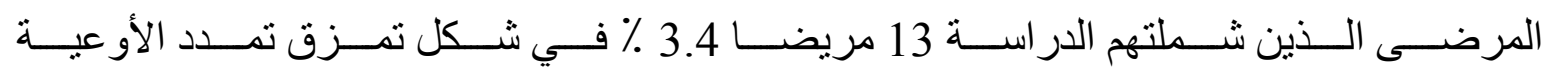
الدموية ، وضياع الملف و استسقاء الر أس وتمزق الثريان.

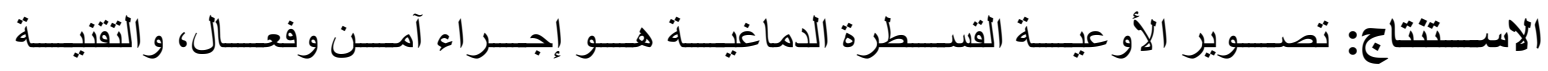

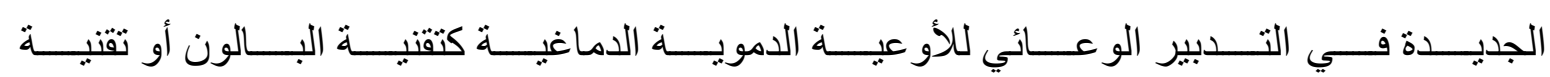

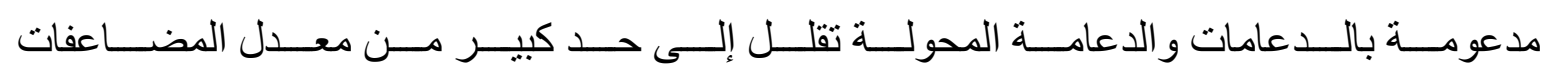
وتجعل النتيجة جيدة للغاية. 